\title{
A study of six representative methods of plasma bilirubin analysis
}

\author{
DEREK WATSON AND JANICE A. ROGERS
}

\author{
From the Biochemistry Department, The Royal Women's Hospital, Melbourne, Australia
}

SYNOPSIS The large number of modern methods which have been published for the determination , of total bile pigments in the blood plasma indicates the difficulties of the estimation and suggests the need for a reliable standard method. In view of the present importance of plasma bilirubin levels in the diagnosis and treatment of jaundiced subjects, six analytical procedures have been studied, each chosen as far as possible, as a representative of a group of methods each embodying different principles.

A spectrophotometric method (White, Haidar, and Reinhold, 1958) and five diazo coupling procedures (Jendrassik and Gróf, 1938; Powell, 1944; Perryman, Richards, and Holbrook, 1957; Stoner and Weisberg, 1957; Lathe and Ruthven, 1958) were investigated, and the results obtained by carrying out duplicate analyses by different methods on 54 stored and 64 fresh plasmas or sera are presented and discussed in this paper.

An amount of haem pigment which can be detected visually in plasma is sufficient to cause a considerable underestimation of bilirubin by the method of Powell (1944) and overestimation by the method of Stoner and Weisberg (1957). Inferences drawn from serial estimations by these methods can therefore be misleading, and this is especially pertinent when results obtained from infant blood containing variable amounts of haem pigments are being assessed. Methods based on the original van den Bergh procedure with various preliminary steps of protein precipitation in alcoholic solutions at about $p \mathrm{H} 4$ give low and poorly reproducible results; losses due to the coprecipitation of bilirubin esters with protein have been confirmed. In our opinion such methods should be abandoned.

Determination of total bilirubin by colour (White et al., 1958) is reliable only for plasma known to contain no lipochrome or 'directly-reacting' pigment; total bile pigment may be overestimated by this technique in plasma containing conjugated bilirubin.

We consider that the method of Lathe and Ruthven (1958) is to be preferred for use on a routine basis. It is conveniently simple, and under all conditions normally encountered gives results sufficiently accurate and reproducible for clinical use. When this or any other procedure is used, a primary standardization between different laboratories with sera containing known amounts of added bilirubin is essential if comparable results are to be obtained.

There is no reliable correlation between the concentration of bile pigments in the plasma and the intensity of clinical jaundice (With, 1954; Culley, Waterhouse, and Wood, 1960). Both the free and the conjugated forms of bilirubin are bound to plasma albumin which, because it pervades cutaneous and other tissues, can cause clinical jaundice. This occurs in adults (with obstructive jaundice) at levels of between 2 and $4 \mathrm{mg}$. bile pigment per $100 \mathrm{ml}$. plasma. In infants with or without haemolytic Received for publication 12 October 1960 disease, the cellular diffusion of the protein-bound pigment appears to be hindered, and a plasma level of 5 to $9 \mathrm{mg}$. bilirubin per $100 \mathrm{ml}$. is often required to produce jaundice.

Serum or plasma bilirubin assays are therefore used to assess the progress of jaundiced subjects, and also to detect small increases of pigment such as may occur in the plasma of cases of early hepatitis, in carriers of homologous serum hepatitis, in some macrocytic anaemias, and in patients receiving treatment with various drugs. A knowledge of bilirubin 
levels is important at the present time for directing the treatment of jaundiced newborn babies, and, partly for this reason, many new micro methods for determining bilirubin levels have recently been devised.

With (1954) reviewed the methods available up to the end of 1951, but since that time no less than 23 new or adaptive procedures have been reported. Although a few of these publications include a mention of a small number of analytical results obtained by the proposed and the parent method, usually that of Malloy and Evelyn (1937) or King and Coxon (1950), no substantial comparative studies appear to have been made.

The work now being reported was undertaken to find out whether appreciable or significant differences in the results of bilirubin analyses exist between different methods, and also to assess the extent and to discover the cause of such variations when present.

\section{THE METHODS}

The methods employed were as follows.

1 The method of Powell (1944) for plasma containing up to about $5 \mathrm{mg}$. bilirubin \% was used as published. In this method, the conventional diazo reagent is added to the plasma, followed by an excess of sodium benzoateurea solution. A plasma blank test is carried out in which dilute $\mathrm{HCl}$ replaces the diazo reagent. Colour densities were read in an EEL colorimeter with Ilford filter 625 . Analyses on the more deeply pigmented plasma were made with $0.5 \mathrm{ml}$. of 1 in 5 saline dilutions of plasma. This method was chosen as a representative of the class employing a non-alcoholic coupling promoter. It was the method routinely used in this hospital at the beginning of our study.

2 The method of Jendrassik and Gróf (1938) was used as published; this is also a non-alcoholic coupling procedure. In it, a solution containing sodium acetate, caffeine, and sodium benzoate is added to plasma followed by a diazo reagent prepared by mixing $0.25 \mathrm{ml}$. nitrite solution with $10 \mathrm{ml}$. of $0.5 \%$ sulphanilic acid in $0.15 \mathrm{~N}-\mathrm{HCl}$. Upon the addition of excess alkali, the pink azo pigments are converted to blue salts. A plasma blank was carried out. The reagent blank was zero. The extinction of the final green solution was read in an EEL colorimeter using an Ilford 607 filter. This was the only departure made from the original method of Jendrassik and Gróf who employed a Pulfrich photometer with filter S61. The method has been re-published in English by Fog (1958a).

3 The method of King and Coxon (1950) modified in a manner suggested by Perryman et al. (1957) was used. Ammonium sulphamate $(0 \cdot 15 \%)$ is incorporated in the diazo reagent and a few crystals of sodium azide are added after the addition of ethanol $(85 \% \mathrm{v} / \mathrm{v})$. Readings are made at $530 \mathrm{~m} \mu$ and $425 \mathrm{~m} \mu$, and the azo pigment extinction is then corrected for interference by haem pigments by means of a simple formula.
As no photomultiplier was available, we used $0.2 \mathrm{~m}$ plasma for every test, giving a final plasma dilution of 1 in 50 compared with 1 in 100 stipulated by Perryma部 et al., and 1 in 10 as used in the original procedure by King and Coxon. The initial plasma dilution was made with water. Optical densities were read on a Unica SP 600 photoelectric spectrophotometer. This methog was chosen as a representative of the class of metho involving deproteinization before diazo coupling.

4 Rice (1957) has suggested that the method of Stoner and Weisberg (1957) for plasma bilirubin estimation ma甲 'fulfil reasonably well the criteria of an ideal analyticat procedure'. This technique also involves deproteinizatiog but uses the measurement of acid blue azo pigments as \& end-point device. It was on this latter account chosen fợ study. Regrettably, it was not found possible to emplo广, the technique as published, because we were unable to obtain a cuvette of $1 \mathrm{~cm}$. stratum length suitable fop measuring optical densities with only $1.7 \mathrm{ml}$. solution The method had therefore to be scaled up. Care ws taken to keep the concentration of the reagents as nearly as possible identical to those of the original procedure We used $0.25 \mathrm{ml}$. diazo reagent and $0.1 \mathrm{ml}$. plasma for tests. Coupling was allowed to proceed in a constricted calibrated centrifuge tube for $10 \mathrm{~min}$., after which $0.3 \mathrm{mp}$ $10 \mathrm{~N}-\mathrm{HCl}$ and $0.5 \mathrm{ml}$. aqueous ammonium sulphate (saturated at the time of use) were added. The volume of solution was made up to $5.0 \mathrm{ml}$. with ethyl alcohal (absolute), the mixture shaken vigorously for $1 \mathrm{~min}$ and then allowed to lie almost horizontally for $15 \mathrm{mi}$ After filtration through Whatman No. 40 paper the optical density of the supernatant fluid was measured at $580 \mathrm{~m} \mu$ against a reagent blank. No serum or plasmita blank is used with this test.

5 The method of Lathe and Ruthven (1958) was used as published. The diazo reagent consists of a mixtu焉 of $0.3 \mathrm{ml}$. of sodium nitrite $(0.5 \%)$ and $10 \mathrm{ml}$. of $1 \%$ sulphanilic acid in $\mathbf{0 . 2} \mathrm{N}-\mathrm{HCl}$. Coupling takes place $50 \%$ methanolic solution. A plasma blank is performeg in which $1 \%$ sulphanilic acid in $0.2 \mathrm{~N}-\mathrm{HCl}$ replaces the diazo reagent. The azo pigment colour usually reaches its maximum intensity about $5 \mathrm{~min}$. after the alcohol ho been added, but with some grossly pigmented specimens up to $9 \mathrm{~min}$. are required. Tests were routinely read $\&$ $10 \mathrm{~min}$. in an EEL colorimeter with an Ilford 624 filta $(525 \mathrm{~m} \mu)$. The method was chosen as a representati of the class of non-precipitation methods employing alcohol as the coupling promoter.

6 Direct spectrophotometric assays were made to duplicate on fresh samples of heparinized plasma by the

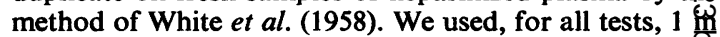
50 dilutions of plasma in $\mathrm{M} / 15$ phosphate buffer $(1 \cdot 74 \mathrm{~g}$. $\mathrm{KH}_{2} \mathrm{PO}_{4}$ and $14.4 \mathrm{~g}$. $\mathrm{Na}_{2} \mathrm{HPO}_{4} 7 \mathrm{H}_{2} \mathrm{O}$ per litre), $p \mathrm{H} 79$. Extinctions were read at 455 and $575 \mathrm{~m} \mu$ in a Unicam SP 600 with $1 \mathrm{~cm}$. matched cells.

STANDARDIZATION OF METHODS The original method Powell is calibrated from one bilirubin solution $(4 \mathrm{mg}$. $\%$, but, as usually employed, it is standardized from density/concentration curve obtained by testing seriô dilutions of a chloroform-alcohol solution of bilirubin place of serum (Varley, 1958). We adopted the formgr

$$
\text { , }
$$


procedure for specimens containing less than about $4 \mathrm{mg}$. \% bilirubin, and the latter for all other tests. In either case, alcohol replaces benzoate-urea as a coupling promoter. The method of Lathe and Ruthven is also standardized from one solution prepared by dissolving a known amount of bilirubin in chloroform. This is then diluted with alcohol and treated in a similar manner to that of the test sample. The method of Perryman et al. employs a buffered methyl red solution as a standard for everyday use. The method of Lathe and Ruthven includes a check on colorimeter responsiveness with the aid of a solution having a constant optical density, i.e., Thompson's neutral grey solution. With the exception of the Stoner and Weisberg and the Jendrassik and Gróf results, our plasma bilirubin results were calculated by reference to the standards advised by the authors of the respective methods. All results were also calculated by reference to standard graphs obtained by the procedures now to be described.

One of us donated blood from which $200 \mathrm{ml}$. of sterile clear yellow serum was obtained. This was used as a medium for stabilizing bilirubin in solution. Our earlier attempts to use discarded transfusion plasma for this purpose were unsuccessful because sodium citrate interfered with some methods of analysis, and a loss of bilirubin was experienced following its addition to glucose-citrated plasma which had been stored for three weeks at $4^{\circ} \mathrm{C}$.

The fresh serum was exposed to ultra-violet light for three periods of two hours on each of three successive days, at the end of which the bilirubin concentration had fallen from its original level of $0.7 \mathrm{mg}$. to one of less than $0.2 \mathrm{mg}$. per $100 \mathrm{ml}$. Forty milligrams bilirubin were rapidly dissolved by stirring in $2 \cdot 0 \mathrm{ml} .0 \cdot 100 \mathrm{~N}-\mathrm{NaOH}$, immediately diluted with about $80 \mathrm{ml}$. serum, mixed with $2 \cdot 0 \mathrm{ml} .0 \cdot 100 \mathrm{~N}-\mathrm{HCl}$, and finally more serum added to make a volume of $100 \mathrm{ml}$. Serial dilutions from this stock solution were made with the original serum diluted with $4 \mathrm{ml}$. $0 \cdot 1 \mathrm{M}-\mathrm{NaCl}$ per $100 \mathrm{ml}$. The standard sera thus prepared contained $2,5,10,15,20,25,30$, and $40 \mathrm{mg}$. bilirubin per $100 \mathrm{ml}$. Using $0.1 \mathrm{ml}$. of these standards, the methods of Powell and Jendrassik and of Gróf were applied. The range between 6 and $35 \mathrm{mg}$. $/ 100 \mathrm{ml}$. was later used for the calculation of the patient's plasma bilirubin. With the method of Lathe and Ruthven, $0.1 \mathrm{ml}$. was used for the range 4 to $16 \mathrm{mg} . / 100 \mathrm{ml}$., and $0.05 \mathrm{ml}$. for levels of 15 to $35 \mathrm{mg} . / 100 \mathrm{ml}$. Of the same standard sera 1 in 50 dilutions were employed to standardize the methods of Stoner and Weisberg, Perryman et al., and White et al. for the complete range of bilirubin concentrations encountered. Before use, the wavelength scale of the Unicam SP 600 was calibrated against a didymium filter according to the makers' instructions. The wavelength scale was considered to be true to $\pm 0.5 \mathrm{~m} \mu$ over the range 420 to $620 \mathrm{~m} \mu$.

A further series of standard sera containing $0 \cdot 5,1 \cdot 0$, $1 \cdot 5,2 \cdot 0,3 \cdot 0,5 \cdot 0,6 \cdot 0$, and $8 \cdot 0 \mathrm{mg}$. bilirubin $/ 100 \mathrm{ml}$. were similarly prepared from a stock serum containing $10 \mathrm{mg}$. bilirubin $/ 100 \mathrm{ml}$., and the analyses carried out on these specimens using $0.4 \mathrm{ml}$. (by the methods of Jendrassik and Gróf and Lathe and Ruthven) and $0.5 \mathrm{ml}$. (by the method of Powell). Blank tests were made on the same volume of the corresponding standard bilirubin serum.

All the standardization procedures were completed within a period of three days. The standard solutions (and subsequently the test plasmas) were analysed at various laboratory temperatures between 17.5 and $19 \cdot 5^{\circ} \mathrm{C}$. Eastman-Kodak bilirubin (batch No. 23A) with a millimolar extinction coefficient of 59.3 in aldehydeand phosgene-free chloroform was used throughout.

THE SPECIMENS FOR ANALYSIS Heparinized blood plasma (10 to 20 i.u. of dry lithium heparin per ml.) was obtained from each of two normal healthy women, nine adults with various liver diseases, and 30 jaundiced infants aged 1 to 7 days. Serum was obtained from the cord blood of each of 13 infants. The specimens were stored at $-10^{\circ} \mathrm{C}$. in the dark until the day before the start of the analyses, when they were transferred to a refrigerator $\left(5^{\circ} \mathrm{C}\right.$.). Twenty-four specimens containing 0.2 to $4 \mathrm{mg}$. $\%$ bilirubin were allowed to warm to room temperature, and then analysed by each of the diazo methods within a period of four days. When not in use, the specimens were stored at $5^{\circ} \mathrm{C}$. in the dark. On the last of the four days, some analyses were repeated to check any loss of bilirubin which might have occurred. Sixteen specimens containing from 4 to $15 \mathrm{mg}$. $\%$ and 15 specimens containing from 15 to $35 \mathrm{mg}$. \% bilirubin were then analysed under similar programmes.

A further series of analyses for pigments was carried out on 64 fresh specimens of heparinized plasma. Tests were made by a chosen diazo-coupling technique and by the spectrophotometric method of White et al. (1958); 'directly-reacting' bilirubin was also estimated by the method of Lathe and Ruthven (1958). Forty-four specimens were obtained from 15 premature babies, eight of whom were jaundiced, and from four infants with erythroblastosis neonatorum, one of whom developed the inspissated bile syndrome. In addition there were six specimens derived from the umbilical cord vein at parturition, and 14 specimens from adult female patients, including cases of toxic hepatocellular disease or obstruction of the common bile duct.

\section{RESULTS}

We were unable to obtain reproducible results by the method of Perryman et al. Varying amounts of unconjugated and conjugated bilirubin were demonstrated by extraction and subsequent diazo coupling to be retained on the precipitate, and the extent of retention was influenced by the amount of shaking given to the mixtures. This variable loss of pigment was also observed when the analyses were carried out as soon as possible after the collection of blood samples from infants with haemolytic jaundice. An examination of the individual results obtained in the duplicate analyses by the other four methods revealed no obvious difference in the reproducibility of the methods. With two exceptions these individual figures were within $3 \%$ of the mean value quoted.

The final coloured solutions from the following 
specimens were opalescent:-Nos. 1, 41, 54 (method of Lathe and Ruthven); Nos. 1, 2, 41, 53, 54 (method of Powell); Nos. 1, 2, 41, 54 (method of Jendrassik and Gróf).
The mean results by the methods of Perryman et al., Powell, and Lathe and Ruthven when calculated from standardizations against bilirubin-containing $\overrightarrow{\overrightarrow{\mathrm{S}}}$ sera are at variance with those calculated as recom-

TABLE I

PLASMA BILIRUBIN LEVELS (MG./100 ML.) OBTAINED BY DIFFERENT METHODS

\begin{tabular}{|c|c|c|c|c|c|c|c|c|}
\hline \multirow[t]{2}{*}{ Sample } & \multicolumn{2}{|c|}{ Perryman et al. (195\%) } & \multirow{2}{*}{$\begin{array}{l}\text { Stoner and } \\
\text { Weisberg }(1957) \\
\text { (b) }\end{array}$} & \multicolumn{2}{|c|}{ Powell (1944) } & \multirow{2}{*}{$\begin{array}{l}\text { Jendrassik and } \\
\text { Gróf }(19.38) \\
\text { (b) }\end{array}$} & \multicolumn{2}{|c|}{ Lathe and Ruthven $(19.58)$} \\
\hline & $(a)^{1}$ & $(b)^{2}$ & & (a) & (b) & & (a) & (b) \\
\hline $1^{3}$ & $0 \cdot 1$ & $0 \cdot 1$ & 0.4 & 0.4 & 0.3 & $0 \cdot 2$ & - & $0 \cdot 3$ \\
\hline $2^{3}$ & $0 \cdot 3$ & $0 \cdot 2$ & 0.5 & 0.4 & $0 \cdot 3$ & 0.3 & - & 0.3 \\
\hline 3D & $3 \cdot 4$ & 3.0 & $4 \cdot 1$ & $4 \cdot 4$ & $4 \cdot 4$ & $3 \cdot 9$ & - & $4 \cdot 7$ \\
\hline 4D & 1.9 & $1 \cdot 5$ & $2 \cdot 6$ & $3 \cdot 1$ & 2.9 & $2 \cdot 7$ & - & 3.0 \\
\hline $5 D$ & 1.9 & 1.5 & $4 \cdot 2$ & $4 \cdot 0$ & 3.9 & $3 \cdot 7$ & - & $4 \cdot 1$ \\
\hline 6 & $1 \cdot 3$ & $1 \cdot 0$ & 1.6 & 1.9 & $1 \cdot 8$ & 1.9 & - & $2 \cdot 1$ \\
\hline 7D & $2 \cdot 9$ & $2 \cdot 4$ & 3.9 & $3 \cdot 8$ & 3.7 & 3.6 & - & 3.9 \\
\hline 8 & 0.9 & 0.8 & $2 \cdot 2$ & $1 \cdot 8$ & 1.6 & 1.5 & - & $1 \cdot 7$ \\
\hline 9D & 1.6 & $1 \cdot 2$ & 2.0 & $2 \cdot 5$ & $2 \cdot 3$ & $2 \cdot 1$ & - & $2 \cdot 4$ \\
\hline 10DH & $1 \cdot 3$ & 1.0 & $2 \cdot 4$ & $2 \cdot 0$ & 1.8 & $2 \cdot 0$ & - & $2 \cdot 1$ \\
\hline $11 \mathrm{H}$ & $1 \cdot 3$ & 1.0 & $2 \cdot 4$ & $2 \cdot 3$ & $2 \cdot 1$ & $2 \cdot 0$ & - & $2 \cdot 3$ \\
\hline $12^{3} \mathrm{H}$ & 1.4 & $1 \cdot 2$ & - & $2 \cdot 2$ & $2 \cdot 0$ & 1.9 & - & $2 \cdot 2$ \\
\hline 13 & $1 \cdot 2$ & $1 \cdot 0$ & $1 \cdot 5$ & $1 \cdot 7$ & $1 \cdot 5$ & $1 \cdot 5$ & - & 1.9 \\
\hline 14D & $2 \cdot 8$ & $2 \cdot 3$ & $2 \cdot 2$ & $2 \cdot 2$ & $2 \cdot 0$ & 1.9 & - & $2 \cdot 7$ \\
\hline 15 & $1 \cdot 7$ & $1 \cdot 3$ & $2 \cdot 6$ & $2 \cdot 1$ & 1.9 & 1.9 & - & $2 \cdot 3$ \\
\hline $16 \mathrm{H}$ & 0.8 & 0.7 & $1 \cdot 5$ & 1.4 & $1 \cdot 2$ & $1 \cdot 4$ & 一 & $1 \cdot 7$ \\
\hline 17DH & $2 \cdot 3$ & 1.9 & 3.6 & $3 \cdot 2$ & 3.0 & $3 \cdot 1$ & - & $3 \cdot 5$ \\
\hline $18 \mathrm{H}$ & 0.8 & $1 \cdot 2$ & $2 \cdot 1$ & $1 \cdot 2$ & $1 \cdot 1$ & $1 \cdot 3$ & - & 1.4 \\
\hline 19 & $1 \cdot 3$ & $1 \cdot 0$ & $2 \cdot 0$ & $2 \cdot 1$ & 1.9 & 1.9 & - & $2 \cdot 3$ \\
\hline 20D & $3 \cdot 1$ & $2 \cdot 7$ & $4 \cdot 4$ & 3.6 & $3 \cdot 5$ & 3.4 & - & 3.9 \\
\hline 21 & $2 \cdot 2$ & 1.8 & $2 \cdot 5$ & $2 \cdot 5$ & $2 \cdot 4$ & $2 \cdot 4$ & - & $2 \cdot 7$ \\
\hline $22 \mathrm{D}$ & $2 \cdot 5$ & $2 \cdot 1$ & $4 \cdot 2$ & 3.6 & $3 \cdot 5$ & $3 \cdot 5$ & - & $4 \cdot 1$ \\
\hline $23^{3}$ & $0 \cdot 4$ & 0.4 & $1 \cdot 2$ & $0 \cdot 3$ & $0 \cdot 3$ & - & - & - \\
\hline Mean of values & $1 \cdot 8$ & $1 \cdot 5$ & $2 \cdot 7$ & $2 \cdot 6$ & $2 \cdot 4$ & $2 \cdot 4$ & - & $2 \cdot 8$ \\
\hline 24D & $3 \cdot 5$ & $3 \cdot 1$ & $4 \cdot 8$ & $4 \cdot 4$ & $4 \cdot 5$ & $4 \cdot 2$ & $4 \cdot 4$ & 4.9 \\
\hline $25 \mathrm{DH}$ & $8 \cdot 1$ & $6 \cdot 3$ & $10 \cdot 5$ & $7 \cdot 9$ & $8 \cdot 5$ & $8 \cdot 7$ & $8 \cdot 5$ & $9 \cdot 5$ \\
\hline 26 & $6 \cdot 3$ & $5 \cdot 3$ & $7 \cdot 6$ & $7 \cdot 0$ & $7 \cdot 4$ & 6.0 & $6 \cdot 3$ & $7 \cdot 1$ \\
\hline 27 & 8.9 & $8 \cdot 2$ & 10.4 & $9 \cdot 2$ & 9.9 & $9 \cdot 2$ & $8 \cdot 8$ & $9 \cdot 9$ \\
\hline 28 & 6.9 & $6 \cdot 1$ & $8 \cdot 2$ & $7 \cdot 1$ & $7 \cdot 6$ & $7 \cdot 3$ & 6.8 & $7 \cdot 6$ \\
\hline 29DG & $2 \cdot 2$ & $2 \cdot 0$ & $5 \cdot 3$ & $3 \cdot 3$ & $3 \cdot 3$ & $3 \cdot 3$ & $3 \cdot 5$ & $4 \cdot 0$ \\
\hline $30 \mathrm{H}$ & $8 \cdot 6$ & $7 \cdot 8$ & $11 \cdot 7$ & $9 \cdot 6$ & $10 \cdot 3$ & $9 \cdot 7$ & $9 \cdot 1$ & $10 \cdot 2$ \\
\hline $31 \mathrm{H}$ & $10 \cdot 8$ & $10 \cdot 0$ & 13.0 & $10 \cdot 2$ & $10 \cdot 9$ & 10.9 & $8 \cdot 8$ & 9.9 \\
\hline $32 \mathrm{H}$ & $10 \cdot 2$ & $9 \cdot 4$ & $12 \cdot 4$ & 10.9 & $11 \cdot 8$ & 11.5 & $10 \cdot 2$ & $11 \cdot 5$ \\
\hline $33 \mathrm{H}$ & $12 \cdot 8$ & $12 \cdot 0$ & 13.9 & $12 \cdot 1$ & $13 \cdot 2$ & 13.5 & $11 \cdot 6$ & 13.0 \\
\hline $34 \mathrm{H}$ & $11 \cdot 6$ & $10 \cdot 7$ & $13 \cdot 6$ & $12 \cdot 0$ & $13 \cdot 1$ & $12 \cdot 4$ & $12 \cdot 8$ & $14 \cdot 2$ \\
\hline $35 \mathrm{H}$ & $12 \cdot 4$ & $11 \cdot 1$ & 15.1 & $10 \cdot 8$ & 11.6 & $13 \cdot 7$ & $12 \cdot 3$ & $13 \cdot 7$ \\
\hline 36 & $10 \cdot 5$ & 9.6 & $12 \cdot 1$ & 10.9 & 11.8 & $11 \cdot 5$ & $10 \cdot 3$ & $11 \cdot 5$ \\
\hline 37 & $11 \cdot 6$ & $10 \cdot 8$ & $12 \cdot 7$ & 12.4 & 13.4 & $12 \cdot 9$ & 11.9 & $13 \cdot 2$ \\
\hline 38D & $13 \cdot 3$ & $12 \cdot 6$ & $17 \cdot 6$ & $12 \cdot 9$ & $14 \cdot 2$ & $15 \cdot 1$ & $12 \cdot 6$ & $14 \cdot 3$ \\
\hline 39 & $14 \cdot 7$ & 14.0 & 13.4 & $12 \cdot 6$ & 13.8 & $13 \cdot 6$ & $13 \cdot 7$ & $15 \cdot 3$ \\
\hline $40 \mathrm{H}$ & $14 \cdot 8$ & $14 \cdot 1$ & $16 \cdot 7$ & $14 \cdot 2$ & $15 \cdot 7$ & 16.8 & 15.9 & $17 \cdot 8$ \\
\hline $41 D L$ & $17 \cdot 2$ & 16.6 & $24 \cdot 1$ & 16.6 & $18 \cdot 8$ & $19 \cdot 2$ & $18 \cdot 2$ & $20 \cdot 2$ \\
\hline $42 \mathrm{H}$ & $14 \cdot 6$ & $13 \cdot 8$ & $18 \cdot 0$ & $14 \cdot 3$ & $16 \cdot 3$ & $16 \cdot 3$ & 14.4 & $16 \cdot 1$ \\
\hline 43 & $14 \cdot 0$ & $13 \cdot 2$ & $15 \cdot 5$ & $14 \cdot 8$ & 16.4 & $15 \cdot 2$ & $14 \cdot 2$ & 15.9 \\
\hline 44 & 15.9 & 15.0 & $18 \cdot 5$ & $15 \cdot 6$ & $17 \cdot 4$ & 16.8 & $15 \cdot 7$ & $17 \cdot 6$ \\
\hline 45 & $14 \cdot 5$ & 13.9 & $17 \cdot 2$ & $15 \cdot 5$ & $17 \cdot 3$ & 16.8 & $15 \cdot 1$ & 16.9 \\
\hline 46 & $18 \cdot 7$ & 18.0 & 23.0 & 20.4 & $24 \cdot 0$ & $23 \cdot 5$ & $21 \cdot 0$ & $22 \cdot 7$ \\
\hline $47 \mathrm{H}$ & $15 \cdot 7$ & 14.9 & $17 \cdot 6$ & 13.7 & 15.0 & $16 \cdot 2$ & $14 \cdot 7$ & $15 \cdot 8$ \\
\hline $48 D$ & 14.0 & $13 \cdot 3$ & 15.6 & 13.9 & $15 \cdot 3$ & $15 \cdot 2$ & $13 \cdot 6$ & $14 \cdot 8$ \\
\hline 49 & 21.9 & $21 \cdot 3$ & $24 \cdot 5$ & $21 \cdot 2$ & $25 \cdot 2$ & $24 \cdot 0$ & $21 \cdot 4$ & $22 \cdot 6$ \\
\hline 50 & 29.0 & $29 \cdot 4$ & $32 \cdot 3$ & $26 \cdot 4$ & $32 \cdot 7$ & $31 \cdot 0$ & $28 \cdot 6$ & $30 \cdot 8$ \\
\hline 51 & $27 \cdot 2$ & $27 \cdot 2$ & $32 \cdot 6$ & $25 \cdot 8$ & $31 \cdot 7$ & $30 \cdot 8$ & $27 \cdot 4$ & $29 \cdot 7$ \\
\hline 52 & $29 \cdot 1$ & $29 \cdot 7$ & 37.0 & 28.0 & $35 \cdot 4$ & 35.0 & 31.9 & $34 \cdot 2$ \\
\hline 53DL & $13 \cdot 0$ & $12 \cdot 3$ & 16.6 & $12 \cdot 8$ & $14 \cdot 1$ & $14 \cdot 2$ & $13 \cdot 3$ & $14 \cdot 4$ \\
\hline $54 \mathrm{DHL}$ & $12 \cdot 2$ & 11.4 & $15 \cdot 2$ & $11 \cdot 6$ & 11.4 & $12 \cdot 5$ & $9 \cdot 7$ & $12 \cdot 6$ \\
\hline Mean of values & $13 \cdot 7$ & $13 \cdot 0$ & $16 \cdot 3$ & $13 \cdot 5$ & $15 \cdot 2$ & $15 \cdot 1$ & $13 \cdot 8$ & $15 \cdot 3$ \\
\hline Mean of all values & $9 \cdot 2$ & $8 \cdot 6$ & $11 \cdot 2$ & $9 \cdot 4$ & $10 \cdot 4$ & $10 \cdot 3$ & - & $10 \cdot 5$ \\
\hline \multicolumn{9}{|c|}{$\begin{array}{l}\text { (a) Standardized as recommended by author(s) of method, and }{ }^{2}(b) \text { standardized as described in text. } \\
{ }^{3} \text { Not included in the calculation of mean values. } \\
\mathbf{D}=\text { containing visually detectable amount of 'direct' pigment. } \\
\mathbf{H}=\text { containing }>0 \cdot 2 \% \text { haemoglobin. } \\
\mathbf{L}=\text { grossly lipaemic specimen. } \\
\mathbf{G}=\text { green specimen. }\end{array}$} \\
\hline
\end{tabular}


TABLE II

EFFECT OF HAEM PIGMENTS AND BILIRUBIN ESTERS IN PLASMA ON SOME TOTAL BILIRUBIN ESTIMATIONS

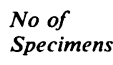
Mean \% Deviation from Approximate True Values ${ }^{1}$

Specimens

\begin{tabular}{llll}
\hline $\begin{array}{l}\text { Perryman et al. } \\
(1957)\end{array}$ & $\begin{array}{l}\text { Stoner and } \\
\text { Weisberg }(1957)\end{array}$ & Powell $(1944)$ & $\begin{array}{l}\text { Jendrassik and } \text { Gróf } \\
(1938)\end{array}$
\end{tabular}

Unhaemolysed plasma

'Direct' pigment

No 'direct' pigment

Total

Haemolysed plasma

'Direct' pigment

No 'direct' pigment

Total

${ }^{1}$ Values obtained by the method of Lathe and Ruthven (1958). mended by the respective authors. Considering the results based on our mode of standardization (Table I), it is apparent that those obtained by the method of Perryman et al. are appreciably lower (0 to $60 \%$ ) than the results found by the other diazo methods. When subjected to a statistical analysis, the results obtained by the remaining methods could be divided into two similar groups: those of Stoner and Weisberg and of Lathe and Ruthven, and those of Powell and of Jendrassik and Gróf. The latter group of values were the lower, and for reasons which will be discussed, it seemed highly probable that the Stoner and Weisberg and the Lathe and Ruthven values were close to the correct results.

Using the values obtained by Lathe and Ruthven's method as a basis, a comparison of all results is shown in Table II, from which it will be seen that bilirubin in haemolysed specimens appears to be overestimated by the method of Stoner and Weisberg, and underestimated by that of Powell. With the method of Perryman et al., total bilirubin is more incompletely estimated in plasma containing 'directly-reacting' pigment than in specimens not containing bilirubin in this form.

During the period of storage, some of the haemoglobin originally present in the haemolysed specimens was converted to other haem pigments. Because this and possibly other protein changes might have affected the analyses, three fresh specimens of heparinized bile-pigmented plasma, each slightly haemolysed, were analysed by the five diazo methods. Each gave results which varied in a similar manner to those obtained on the stored plasma.

Table III summarizes the results obtained for bile pigments on 64 fresh samples of plasma. The specimens from the jaundiced adults and one infant contained large amounts of 'directly-reacting' bilirubin. In these instances the mean pigment

TABLE III

PLASMA BILE PIGMENT LEVELS DETERMINED SPECTROPHOTOMETRICALLY AND BY DIAZO COUPLING

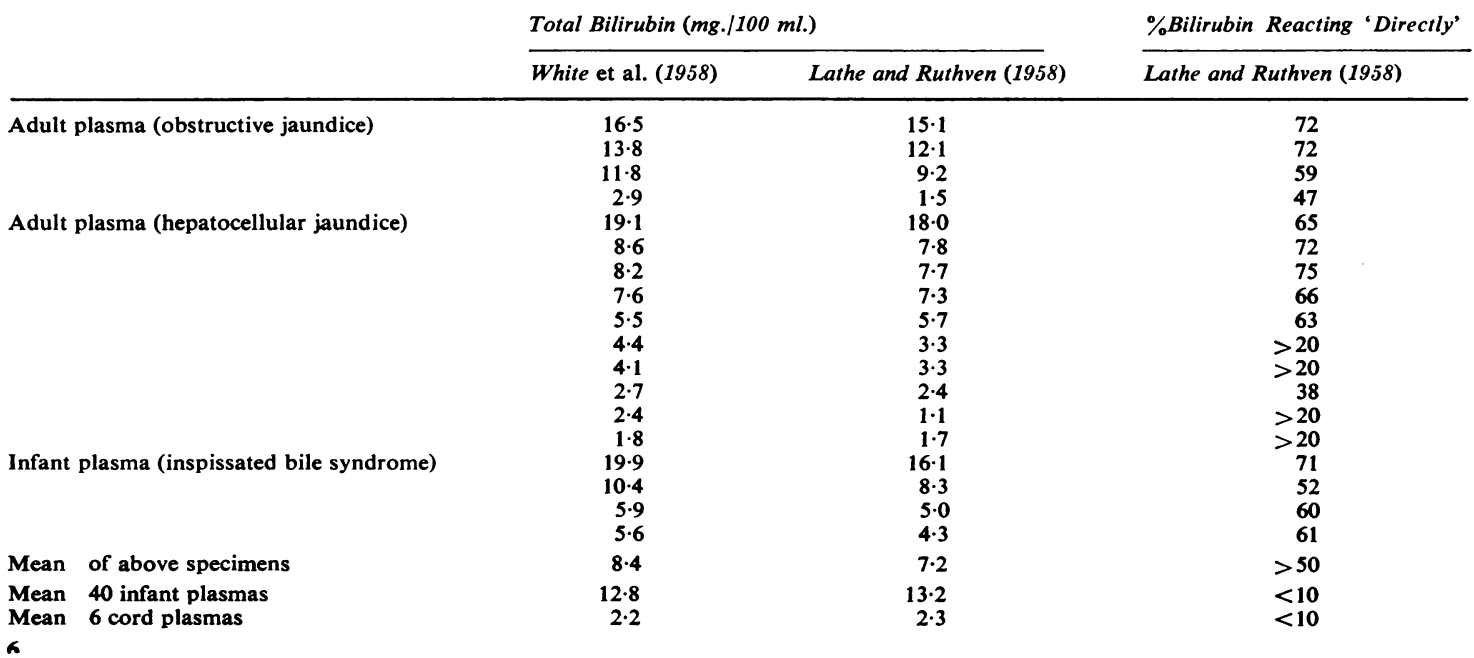


concentration found by spectrophotometric analysis (method of White et al.) exceeded that found by diazo coupling (method of Lathe and Ruthven) by from 0 to $93 \%$ (mean, $16 \%$ ).

With the exception of the case of inspissated bile syndrome, all the infant plasma (from capillary and cord blood) contained less than $10 \%$ of pigment which reacted 'directly', Total bile pigment ranged from 1.8 to $29.1 \mathrm{mg}$./ $100 \mathrm{ml}$. The mean pigment level found spectrophotometrically in these specimens was $96.5 \%$ (S.E. of mean $0.8 \%$ ) of that obtained by the diazo method.

\section{DISCUSSION}

DIAZO METHODS WITH PROTEIN PRECIPITATION The claim of Perryman et al. (1957) that absorption of bilirubin esters on the precipitated protein can be prevented by decreasing the serum concentration in the reaction mixture to $1 \%$ has not been confirmed by the present work. Several of our stored plasmas were tested in parallel on dilutions of 1 in 20 and 1 in 100 , and were found to give almost identical results. Tests on plasma from freshly drawn blood also gave low results, so that it is unlikely that denaturation of protein during the storage period was responsible for the poor results.

The time allotted for the development of the azopigment colour in the method of Perryman et al. is $5 \mathrm{~min}$. We allowed $10 \mathrm{~min}$. since this was more convenient for batch analyses. An extension of this period to $30 \mathrm{~min}$. (the time employed by King and Coxon) produced no appreciable increase in azopigment density, and the omission of the "few crystals of sodium azide' to destroy excess diazonium compound also had no effect on the final pigment density. In the procedure of Perryman et al. the other deviation from that of King and Coxon's method is the addition of $1 \mathrm{ml}$. of $1.5 \%$ ammonium sulphamate to $10.3 \mathrm{ml}$. of diazo reagent before use. This modification was first suggested by Patterson, Swale, and Maggs (1952) as a means of destroying excess nitrous acid. We were unable to detect excess nitrite in the diazo reagent of King and Coxon, which is not surprising in view of the fact that the reagent contains only $38 \%$ of the theoretical nitrite requirement of the sulphanilic acid. The omission of the ammonium sulphamate had no effect on the analysis.

Two comparative studies (Patterson et al., 1952; Lathe and Ruthven, 1958) have previously indicated that the bilirubin values obtained by the method of King and Coxon (1950) are lower than those found by some non-precipitation methods. From the present work it appears that this type of precipitation method is incapable of accurately determining serum or plasma bilirubin. That this has not been generally recognized is partly due to the fact that: with King and Coxon's method, non-specifies? chromogens in the aqueous alcohol extract ofteno contribute to the final colour, thereby improving the apparent bilirubin result.

The methyl red solution of Haslewood and King (1937) employed as a standard by Perryman et alo (1957) did not in our hands match the shade of colour or the optical density of the azo pigments derived from the quoted concentration of our bili $\vec{\omega}$ rubin preparation when the latter was prepared as a. standard bilirubin serum. We found (with the methodg of Perryman et al.) very close agreement between-

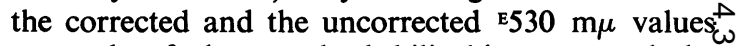
on each of the standard bilirubin sera, and theit bilirubin results obtained for haemolysed and nonhaemolysed plasma seem to indicate that the haem-o pigment correction formula is adequate (see TableII).

In the case of Stoner and Weisberg's method, acick haematin when present in the final solution absorbs appreciably at $580 \mathrm{~m} \mu$, the wavelength at which the blue pigments are measured. This would account for the higher values obtained by this rather than byo Lathe and Ruthven's method, since the latter is relatively unaffected by haem pigments (Watson 1960). We noted that small but variable opticalo readings could be obtained with blank tests on different plasma containing approximately the sameo흘 amount of bilirubin, but the matter was not further investigated.

DIAZO METHODS WITHOUT PROTEIN PRECIPITATIONO The methods of Jendrassik and Gróf (1938) and of Powell (1944) are modifications of a method devised 3 . by Enriques and Sivó (1926) in which the coupling promoter is sodium benzoate. Such methods have? been criticized on the grounds that the final colourso are sometimes 'impure' (King and Coxon, 1950), and that they require several hours for the completeo coupling of serum bilirubin in cases of haemolytic jaundice (Gray, 1953; Stoner and Weisberg, 1957) In our experience these criticisms apply to thoseN modifications of Enriques and Sivó's method in which sodium benzoate has been omitted in favour $\omega$ of a less efficient coupling promoter, e.g., caffeine or citrate (Rappaport and Eichhorn, 1943; Gray and Whidborne, 1946; Chabrol, Böszörményi, and Fallot, 1949). During the course of several thousand bilirubin analyses at this hospital byo Powell's method, we have never observed 'impure' colours, nor have we been able to detect any further $\frac{?}{\mathbb{D}}$ increase in azo pigment density with time. Neverthe- $\frac{0}{2}$ less, false low bilirubin values are obtained by Powell's method if the plasma contains traces of 
haemoglobin or haem pigments. This effect is caused by interference with coupling, rather thanas was suggested by Sims and Horn (1958)-excessive 'blank' correction. Since with fresh haemolysed plasma (naturally or artificially bile pigmented) we have observed larger underestimates of bilirubin by Powell's method (Watson, 1960) than were actually found with the stored specimens, it is possible that some conversion products occurring in our specimens as a result of storage in deep-freeze interfere to a lesser extent with bilirubin coupling than haemoglobin does.

The final solutions of the Malloy and Evelyn (1937) procedure derived from lipaemic plasma or specimens containing normal concentrations of bilirubin are occasionally opalescent, and it is generally agreed that the intensity of this turbidity may vary between the 'blank' and the 'test' determinations. As previously stated, we observed opalescence with Lathe and Ruthven's method, but the benzoate methods of Powell, and Jendrassik and Gróf were also equally subject to this source of error.

Several methods of bilirubin analyses, including those of Powell (1944), Dangerfield and Finlayson (1953), Sims and Horn (1958), and Brückner (1959), employ insufficient diazo reagent to hydrolyse and couple all the bilirubin in deeply bile-pigmented plasma, unless a smaller volume of plasma than that stipulated is taken for analysis (Watson, 1961). Lathe and Ruthven in their method suggest using half the quantity of plasma for specimens containing more than $15 \mathrm{mg}$. total pigment per $100 \mathrm{ml}$. However, there is nothing obligatory or distinctive in the change at $15 \mathrm{mg}$., since the method employs per millilitre of plasma much higher final concentrations of diazotised and undiazotised sulphanilic acid than is used in the parent method of Malloy and Evelyn (1937). On the other hand, when inadvertently using $0.1 \mathrm{ml}$. plasma containing more than $20 \mathrm{mg}$. bilirubin per $100 \mathrm{ml}$., we have encountered some plasma specimens from which the appearance of maximum azo pigment colour was delayed for 15 to $20 \mathrm{~min}$. Contrary to the contention of Meites and Hogg (1959), we found it an advantage to use different plasma concentrations because it enabled us to read the final optical densities more accurately. For this reason also, we used a volume of $0.4 \mathrm{ml}$. for plasma which appeared to contain normal or only slightly above normal concentrations of bile pigment.

Meites and Hogg (1959), using the method of Malloy and Evelyn (1937), have shown that when the temperature at which the analysis is performed is dropped from $22^{\circ} \mathrm{C}$. to $10^{\circ} \mathrm{C}$., the production of azo pigments from serum bilirubin is decreased by about $50 \%$. The density of the azo pigments produced from chloroform solutions of bilirubin under similar conditions, however, does not vary by more than $5 \%$. Since in our laboratory, room temperatures fluctuate from $13^{\circ} \mathrm{C}$. to $26^{\circ} \mathrm{C}$. during the year, Malloy and Evelyn's method would require careful temperature control, or standardization at different temperatures with bilirubin sera, procedures inconvenient for routine use. A modified reagent which reacts maximally in this temperature range has been proposed, but unfortunately the results obtained with it are very considerably affected by subvisible amounts of haemoglobin in serum (Meites and Hogg, 1959). Using the method of Lathe and Ruthven we have observed that no decrease occurs in the production of azo pigment from plasma containing bilirubin as a result of a fall in the laboratory temperature. Moreover, this method has been shown not to be significantly affected by haemolysis (Watson, 1960).

The method of Jendrassik and Gróf has been stated to have a high degree of specificity and reproducibility (With, 1954; Fog, 1958a). If we assume that the bilirubin levels found by this method are correct, then the results obtained by the method of Stoner and Weisberg, Lathe and Ruthven, and Powell on unhaemolysed specimens will be 5 to $10 \%$ too high. The occurrence of side reactions producing yellow and brown diazo products with urobilinogen (Lopez Garcia, 1941) and with some non-protein nitrogen compounds (Harrison and Bromfield, 1928) have been reported. But these reactions cannot here account for an overestimation of pigment by the three methods, since, with the exception of plasma No. 9, none of our specimens was azotaemic, and it is more likely that the infant plasma tested contained lower rather than higher than average concentrations of urobilinogen. Caffeine-benzoate coupling methods have previously been reported to give lower values than those found by some alcohol coupling methods (Malloy and Evelyn, 1937; Ducci and Watson, 1945). It is therefore possible that some substance present in the plasma of jaundiced patients (and absent from normal serum fortified with bilirubin) may inhibit the coupling of bilirubin under the conditions of Jendrassik and Gróf.

Results based on standardizations from chloroform solutions and serum solutions of bilirubin differed by approximately $9 \%$ (methods of Powell and of Lathe and Ruthven). In chloroform solutions, the relative extinction of 'azobilirubin' was higher than in serum solutions; the coupling promoter used in each case was $50 \%$ methanol. Using $80 \%$ ethanol, O'Hagan, Hamilton, Le Breton, and Shaw (1957) observed $2 \%$ lower azo pigment densities with choroform bilirubin solutions than with the same quantities of bilirubin in serum (method of Powell). Although there is no doubt that changes in the spectral curves produced by variations in solvent 
and $p \mathrm{H}$ are the cause of part of the discrepancies, we are unable to account satisfactorily for the large differences. Experiments in which bilirubin was added to bile-pigmented plasma have always yielded $100 \pm 2 \%$ recovery.

SPECTROPHOTOMETRIC METHOD Higher total bile pigment levels for adult plasma were obtained by spectrophotometry by the method of White et al. than by diazo coupling by the method of Lathe and Ruthven. This is contrary to the opinion of White $e t$ al. (1958) but in agreement with the findings of Fog (1958b) who measured pigment colour by a more refined procedure (Fog, 1949). On the other hand, the bile pigment levels obtained by the diazo and spectrophotometric methods showed good agreement in plasma obtained from infants (both icteric and non-icteric) during the first week of life. An exception was the infant with the inspissated bile syndrome (whose plasma bile pigment was mainly in the conjugated form). Since infant plasma is almost devoid of lipochromes (Mertz and West, 1956), it would appear that estimation by the method of White et al. (1958) includes in addition to lipochromes when present, a measure of non-bilirubin pigments which are exclusively found in plasma containing an appreciable percentage of bilirubin reacting 'directly' by the method of Lathe and Ruthven. These pigments may be dipyrroles, e.g., bilifuscin or allied pigments as suggested by With (1954), or possibly bilirubin esters or non-diazo coupling tetrapyrroles with a bigher specific extinction coefficient than unconjugated bilirubin.

\section{CONCLUSIONS}

Haem pigment known to be present in many specimens of infant plasma causes the method of Powell (1944) to underestimate and that of Stoner and Weisberg (1957) to overestimate the plasma bilirubin concentration.

Bilirubin methods incorporating protein precipitation, e.g., that of King and Coxon (1950), and modifications, give low and variable results.
Results obtained by spectrophotometry (White $e \stackrel{\vec{D}}{\overrightarrow{0}}$ $a l ., 1958)$ are satisfactory for infant plasma, provided" no appreciable amounts of 'directly-reacting' bili $\stackrel{\overrightarrow{9}}{\rightarrow}$ rubin are present.

Experience with several techniques has led us tof choose that of Lathe and Ruthven (1958) as the most suitable and valid general-purpose method ato present available for the determination of plasma bilirubin.

We thank Dr. G. Gregory of the University of Melbournefor assistance with the statistical analysis of the results $\vec{\omega}$

\section{REFERENCES}

Brückner. J. (1959). Amer. J. clin. Path., 32, 513.

Chabrol, E Böszörményi, M and Fallot, P. (1949). Sem. Hôp. Pari iN $25,3437$.

Culley, P. E., Waterhouse, J. A. H., and Wood, B. S. B. (1960) Lancet, 1, 88.

Dangerfield, W. G., and Finlayson, R. (1953). J. clin. Path., 6, 173Ducci, H., and Watson, C. J. (1945). J. Lab. clin. Med., 30, 293.

Enriques, E., and Sivó, R. (1926). Biochem. Z., 169, 152.

Fog, J. (1949). Scand. J. clin. Lab. Invest., 1, 255.

(1958a). Ibid, 10, 241. (1958b). Ibid, 10, 246

Gray, C. H. (1953). The Bile Pigments. Methuen, London. $\longrightarrow$, and Whidborne, J. (1946). Biochem J., 40, 81.

Harrison, G. A., and Bromfield, R. J. (1928). Ibid, 22, 43.

Haslewood, G. A. D., and King. E. J. (1937). Ibid. 31, 920.

Jendrassik, L., and Gróf, P. (1938). Biochem. Z., 297, 81.

King, E. J., and Coxon, R. V. (1950). J. clin. Path., 3, 248.

Lathe, G. H., and Ruthven, C. R. J. (1958). Ibid., 11, 155.

Lopez Garcia, A. (1941). Medicina (B. Aires), 1, 219. Quoted b With (1954) vide infra.

Malloy, H. T., and Evelyn, K. A. (1937). J. biol. Chem., 119, 481. $\overrightarrow{\vec{\sigma}}$

Meites, S., and Hogg, C. K. (1959). Clin. Chem., 5, 470.

Mertz, J. E., and West, C. D. (1956). A.M.A. Amer. J. Dis. Child., 91 19.

O'Hagan, J. E., Hamilton, T., Le Breton, E. G., and Shaw, A. E (1957). Clin. Chem., 3, 609.

Patterson, J., Swale, J., and Maggs, C. (1952). Biochem. J., 52, $10 \mathrm{C}^{\circ}$

Perryman, P. W., Richards, D. H., and Holbrook, B. (1957). Ibid! 66, 61P.

Powell, W. N. (1944). Amer. J. clin. Path., 14, Tech. Sect., 8, 55.

Rappaport, F., and Eichhorn, F. (1943). Lancet, 1, 62.

Rice, E. W. (1957). Clin. Chim. Acta, 3, 121.

Sims, F. H., and Horn, C. (1958). Amer. J. clin. Path., 29, 412.

Stoner, R. E., and Weisberg, H. F. (1957). Clin. Chem., 3, 23.

Varley, H. (1958). Practical Clinical Biochemistry, 2nd ed. Heinemanno음 London.

Watson, D. (1960). Clin. Chim. Acta, 5, 613.

(1961). Clin Chem., 7, 234.

White, D., Haidar, G. A., and Reinhold, J. G. (1958). Ibid, 4, 211. N With, T. K. (1954). Biology of Bile Pigments. Frost-Hansen, Copero hagen. 